\title{
RETHINKING RESPONSIBILITY FOR PATIENT INJURY: ACCELERATED- COMPENSATION EVENTS, A MALPRACTICE AND QUALITY REFORM RIPE FOR A TEST
}

\author{
Laurence R. Tancredi* and Randall R. BovbjerG**
}

I

\section{INTRODUCTION: THE NEED fOR REFORM}

The conventional malpractice system has many problems, and complaints about law and lawyers are hardly new. ${ }^{1}$ Today, however, tort law operates on a broad scale, has widespread economic impact through liability insurance, and influences access to medical care and the nature of medical practice. ${ }^{2}$

In brief, the sometimes erratic, usually slow, and always expensive process of today's payment system undercuts its ability to compensate victims. Its failure to reach most avoidable injuries, its seemingly haphazard case-by-case determinations, and its lack of scientific legitimacy hamper its ability to deter injury. The system thus fails to achieve the two main goals of tort law. ${ }^{3}$ Moreover, providers' mistrust of the system encourages wasteful and even harmful "defensive medicine," which is the main reason for health policy concern. ${ }^{4}$ Meanwhile, quality control is unduly divorced from the malpractice

Copyright (C) 1991 by Law and Contemporary Problems

* Kraft Eidman Professor of Medicine and the Law, and Director, Health Law Program, University of Texas Health Science Center, Houston, Texas.

** Senior Research Associate, The Urban Institute, Washington, D.C.

This article reports on a study principally funded by the Robert Wood Johnson Foundation, grant no. 124I I, as well as support from the University of Texas Health Science Center at Houston, for Dr. Tancredi's time, which support is gratefully acknowledged. The authors wish to acknowledge their current Urban Institute colleagues Daniel S. Gaylin and Philip J. Held, together with earlier colleagues in the development of ACEs, particularly Clark C. Havighurst of Duke Law School, as well as Dr. John R. Boyden of Salt Lake City and James A. Henderson, Jr., of Cornell Law School. The authors also want to thank their medical consultants, most notably Drs. Bruce D. Browner, Robert K. Creasy, and Frank G. Moody of the University of Texas Health Science Center at Houston.

1. See, for example, Jeffrey O'Connell, The Lawsuit Lottery: Only the Lawyers Win (Free Press, 1979); Randall R. Bovbjerg, Medical Malpractice on Trial: Quality of Care Is the Important Standard, 49 L \& Contemp Probs 321 (Spring 1986); George L. Priest, The Current Insurance Crisis and Modern Tort Law, 96 Yale L J 1521 (1987).

2. See, for example, Institute of Medicine, 1-2 Medical Professional Liability and the Delivery of Obstetrical Care (Nat'l Acad Press, 1989); Robert E. Litan \& Peter W. Huber, eds, The Liability Maze: The Impact of Liability Law on Safety and Innovation (Brookings Institution, 1991).

3. See, for example, Warren A. Seavey, W. Page Kecton \& Robert E. Keeton, Cases and Materials on the Law of Torts 1 (West, 1957).

4. Dep't of Health, Educ \& Welfare, Report of the Secretary's Commission on Medical Malpractice (Gov't Printing Office, 1973); Laurence R. Tancredi \& Jeremiah A. Barondess, The Problem of Defensive 
system, even as there are grave concerns about the prevalence of iatrogenic injury and negligence. ${ }^{5}$

Hence, reform is very definitely in order. However, reforms need to offer a demonstrable improvement, not merely "less of the same," like conventional tort reform's pro-defendant changes in legal rules. ${ }^{6}$ Some conventional tort reform does make a difference, reducing claims and payments. ${ }^{7}$ Yet it can be attacked, politically and constitutionally, as a "takeaway" with insufficiently compensating benefit. ${ }^{8}$ Moreover, conventional reform can neither improve deterrence and compensation nor allay providers' defensiveness toward the conventional legal process. 9 Better reforms would address more of the avoidable bad outcomes in medicine, resolve medical injuries more fairly and cheaply, and discourage defensive medicine. This article reports on the current state of the art with regard to a leading type of malpractice reform. We argue that reforms based on "acceleratedcompensation events" ("ACEs") 10 would best address the twin goals of making compensation more equitable and avoiding bad outcomes in medical care. Part II provides a general introduction to ACES; Part III outlines and Part IV evaluates the potential advantages and disadvantages of ACE-based

Medicine, 200 Science 879 (1978); Congressional Res Serv, US Congress, Medical Malpractice: A Report Prepared at the Request of the House Committee on Ways E' Means 101-26 (Gov't Printing Office, April 16, 1990).

5. Don Harper Mills, John S. Boyden \& David S. Rubsamen, Report on the Medical Insurance Feasibility Study (Sutter, 1977) (sponsored jointly by the California Medical and Hospital Associations), summarized in Don Harper Mills, Medical Insurance Feasibility Study-A Technical Summary, 128 W J Med 360 (1978) ("Report on the Feasibility Study"); see generally Harvard Medical Practice Study, Patients, Doctors, and Lawyers: Medical Injury, Malpractice Litigation, and Patient Compensation in New York ch 6 (Harvard U Press, 1990) (report of the Harvard Medical Practice Study to the State of New York) ("Patients, Doctors, and Lawyers").

6. Randall R. Bovbjerg, Legislation on Medical Malpractice: Further Developments and a Preliminary Report Card, 22 UC Davis L Rev 499 (Spring 1989), reprinted in 3 Nat'l Ins L Rev 217 (Autumn 1989).

7. There is growing consensus that the "big three" of tort reforms are caps on awards, changes in the statute of limitations, and collateral source offset. See, for example, Patricia M. Danzon, The Frequency and Severity of Medical Malpractice Claims: New Evidence, 49 L \& Contemp Probs 57 (Spring 1986); Frank A. Sloan \& Randall R. Bovbjerg, Medical Malpractice: Crises, Response and Effects, Health Ins Ass'n Am Res Bull (May 1989) (summarizing findings as of early 1989); Stephen Zuckerman, Randall R. Bovbjerg \& Frank A. Sloan, Effects of Tort Reforms and Other Factors on Medical Malpractice Insurance Premiums, 27 Inquiry 167 (Summer 1990).

8. See, for example, James F. Blumstein \& David R. Smith, Constitutional Attacks on Medical Malpractice Laws, in L. Andrew, ed, Legal Liability and Quality Assurance in Newborn Screening (1985) ("Constitutional Attacks").

9. Randall R. Bovbjerg, Problems and Solutions in Medical Malpractice, in Robert E. Litan \& Peter W. Huber, eds, The Liability Maze: The Impact of Liability Law on Safety and Innovation 274-90 (Brookings Institution, 1991) ("Problems and Solutions").

10. Earlier in ACE development, the American Bar Association Commission popularized the term "designated compensable events," or DCEs. Am Bar Ass'n Commission on Medical Professional Liability, Designated Compensable Event System: A Feasibility Study (Am Bar Ass'n, 1979) ("Feasibility Study"). Others subsequently followed this nomenclature. See, for example, Am Med Ass'n, A Proposed Alternative to the Civil Justice System for Resolving Medical Liability Disputes: A Fault-Based, Administrative System (Am Med Ass'n, 1988) (Special Society Medical Liability Project) ("A Proposed Alternative"). The DCE nomenclature emphasized the AMA process of designating ACEs. At this stage of seeking to implement ACE systems as a payment reform, among other uses, it is more appropriate to emphasize ACEs' major benefit of accelerating compensation. 
reforms. Finally, Part V describes some practical prerequisites to a successful implementation of such reforms.

II

\section{“AcCelerated-Compensation Events" as a Reform}

Accelerated-compensation events are medically caused injuries that should not normally occur. ${ }^{11}$ ACEs do not cover all injuries, just classes of adverse outcomes that are usually, although not invariably, avoidable through good care. ${ }^{12}$ Medical experts create ACEs by reviewing information on injuries, then generalizing to sets of events that qualify for designation as ACEs. ${ }^{13}$ The ACE concept is now in its third generation of development. ${ }^{14}$ Initial, largely conceptual work occurred in the early 1970 s. $^{15}$ Later in that decade, the first two detailed ACE listings were developed and their feasibility analyzed, using limited information compiled on malpractice insurance claims. ${ }^{16}$ The most recent research on ACE approaches has developed additional listings and undertaken more thoroughgoing research about the likely effects of ACEs, in the first empirical application of the ACE alternative to "real world" cases. ${ }^{17}$

11. The focus on events that should not normally occur is not unique to ACEs. Since the mid1970 s, Sweden has had a nontort compensation system for certain medical injuries that are not the unavoidable consequences of medical care. See, for example, Eva D. Cohen \& Samuel P. Korper, The Swedish No-Fault Patient Compensation Program: Provisions and Preliminary Findings, 1976 Ins L J 70. However, the Swedish scheme excludes injury from drugs and diagnosis; it also makes case-by-case decisions rather than creating a list in advance.

12. ACEs thus do not embody true no-fault principles, but rather constitute a selective no-fault approach when used for reform of malpractice payment. ACEs focus predominantly on statistical "avoidability." See footnotes 19, 23 for discussion of this issue. Some adverse outcomes of medical care are unavoidable. An illustration would be a patient who undergoes an unexpected cardiac arrest during general surgery, despite appropriately conducted pre-surgery diagnostic studies that failed to reveal evidence of existing cardiac disease.

13. On the creation of ACE lists, see especially Laurence R. Tancredi \& Randall R. Bovbjerg, Creating a Selective No-Fault System for Malpractice and Quality Reform: Methodology of AcceleratedCompensation Events (ACES) (working paper 1991) ("Creating a Selective System"); Laurence R. Tancredi, Identifying Avoidable Adverse Events in Medicine, 12 Med Care 935 (1974); see generally sources cited at notes 14-22.

14. For an extended descriptive analysis of ACE development, see Tancredi \& Bovbjerg, Creating a Selective System (cited in note 13).

15. Laurence R. Tancredi, The Analytics of a No-Fault System for Medical Malpractice: A Medical Outcome Insurance System, (Yale Law School honors thesis, unpub 1972); Clark C. Havighurst \& Laurence R. Tancredi, Medical Adversity Insurance-A No-fault Approach to Medical Malpractice and Quality Assurance, 51 Milbank Mem Fund Q 125 (1974), reprinted in 1974 Ins L J 69; Clark C. Havighurst, "Medical Adversity Insurance"-Has Its Time Come?, 1975 Duke L J 1233; Tancredi, 12 Med Care 935 (cited in note 13).

16. John R. Boyden, Jr., \& Laurence R. Tancredi, Identification of Designated Compensable Events (DCEs), in Am Bar Ass'n Comm'n on Medical Professional Liability, Designated Compensable Event System: A Feasibility Study 11-51 (Am Bar Ass'n, 1979) (using insurance data, medical literature, and physician panel judgment) ("Identification of DCEs"). One listing was also developed by Sue Rankin, see Havighurst, 1975 Duke L J at 1256-59 (cited in note 15) (using medical literature).

17. See generally Tancredi \& Bovbjerg, Creating a Selective System (cited in note 13); Randall R. Bovbjerg, Laurence R. Tancredi \& Daniel S. Gaylin, Obstetrics and Malpractice: Evidence on the Performance of a Selective No-Fault System, 265 J Am Med Ass'n 2835 (1991). Others have also suggested ACE or ACE-like systems. See James A. Henderson, The Boundary Problems of Enterprise Liability, 41 Md L Rev 659 (1982) (describing DCE approach). Professor Henderson was a contributor to the American Bar Association Commission report. See Am Bar Ass'n, Feasibility Study at 4 (cited in note 10); Barry M. Manuel, Professional Liability-A No-Fault Solution, 322 New Eng J Med 627, 628 (1990) 
The three main criteria for listing an adverse medical outcome as an ACE are: ${ }^{18}$ (1) avoidability: events are medically caused and moderately or highly preventable as a class ${ }^{19}$; (2) detectability: each ACE class is readily specified, with clear boundaries that exclude similar non-ACEs; and (3) absence of bad incentive effects: ${ }^{20}$ listing as an ACE does not distort medical decisionmaking.

The ACE approach differs markedly from conventional litigation or settlement of liability insurance claims. The current system is based on afterthe-fact, individualized determinations of fault by lay jurors. In contrast, ACEs are based on an advance listing of professionally selected classes of bad outcomes deemed usually avoidable on a probabilistic basis. The law relies on idiosyncratic testimony about allegedly faulty processes of care in particular cases. ACE categories rely on generalized expert judgment about statistical outcomes of medical care. In addition, the law uses a formalized adversary process, ultimately conducted in courtrooms. The ACE process, depending on the precise type of reform instituted, is meant to resemble practices of private or public insurers in resolving non-liability claims. ${ }^{21}$ ACEs, being grounded in medical outcomes, also differ from most approaches to quality monitoring and assessment in medicine.

The classic prototypical ACE is a surgical instrument unintentionally left within a patient, although many less obvious events are also included. Experts can agree that such events should not normally occur, given good care. In any particular case there may be a reasonable explanation for how an instrument was left despite good care, but an ACE-based system seeks to avoid such expensive and slow investigation and arguments. Table 1 lists the eleven overall categories of ACEs, such as "Nerve Injuries" and "Puncture or Laceration Wounds." Each category is illustrated with a simplified description of a sample ACE class. Recent research has developed an ACE listing for obstetrics and gynecology, and has improved upon earlier listings for general surgery and orthopedic surgery. ${ }^{22}$ For example, experts reviewing adverse events in obstetrics and gynecology agreed in advance on forty-eight

(calling for boards of physician-specialists to create "list of approved compensable medical injuries"); Larry M. Pollack, Medical Maloccurrence Insurance (MMI): A No-Fault Insurance Proposal for Resolving the Medical Malpractice Controversy, 1988 Tort \& Ins L J 552.

18. Tancredi \& Bovbjerg, Creating a Selective System (cited in note 13).

19. In our most recent work on creating lists of ACEs, the definition applied was $70 \%$ or more avoidable. Id. However, different definitions could be applied for different purposes or according to differing judgment about the relative importance to the system of opposite shortcomings-failing to include avoidable injuries versus including some that are not avoidable.

20. In this way, ACEs seek to avoid creating motivations to practice a kind of defensive medicine. See discussion at notes 91-95 and accompanying text.

21. On the different possible types of ACE-based reform, see discussion at notes 25-28 and accompanying text. ACEs used as an alternative payment system for malpractice also feature different rules of damages. See discussion at notes 107-14 and accompanying text.

22. Table 1, adopted from Tancredi \& Bovbjerg. Creating a Selective System (cited in note 13), is drawn from the three ACE listings: "ACE's for Surgery, 11/30/89," "ACE's for Orthopedic Surgery, 11/21/89," and "ACE's for Obstetrics and Gynecology, 01/17/90," all copyright University of Texas Health Science Center at Houston (copy on file with authors). These three specialties are the top three in terms of numbers of claims against physicians. See discussion accompanying note 96. 
classes of adverse outcomes for their specialty, grouped within the eleven major categories.

\section{TABLE 1}

\section{Categories of ACEs with Sample Listings}

\section{INFECTIONS}

Decubitus ulcer during inpatient care.

II. NERVE INJURIES

Complications (blindness, brain damage) secondary to air embolisms during surgical removal of an acoustic neuroma.

III. OTHER COMPLICATIONS OF PROCEDURES

Infarction of bowel secondary to hernia repair.

IV. PUNCTURE OR LACERATION WOUNDS

Complications (including death) from pneumothorax following subclavian venopuncture and closed thoracotomy.

V. JOINT AND DEVICE MISPLACEMENT

Postoperative displacement of any internal orthopedic device which was applied during that operative procedure.

VI. DRUG AND BLOOD DISORDERS

Complications (for example, hypotension, shock, or death) secondary to anticoagulant treatment in preparation for surgery.

VII. FAILURE TO DIAGNOSE

Complications from failure to diagnose and treat hypoglycemia in a newborn.

VIII. FOREIGN BODIES

Complications (including death) from foreign body unintentionally left in the operative site after any surgical operation or procedure.

IX. FALLS

Complications from falls from table during surgical operation or procedure or during childbirth.

X. VASCULAR EVENTS

Complications (severe edema, pulmonary embolism, etc.) secondary to phlebitis and thrombophlebitis (deep vessels of lower extremities) following a surgical procedure.

XI. DEATH

Death during surgical operations (or immediately after) other than with a high risk patient.

Source: ACE Listings for Obstetrics/Gynecology, General Surgery, and Orthopedic Surgery, (c) University of Texas, cited in note 22. Adapted from Tancredi \& Bovbjerg, Creating a Selective System (cited in Note 13).

ACEs can be used in a variety of ways, from replacing much of tort law to assisting medical quality review. More specifically, the options include ACEbased reforms in payment, dispute resolution, insurance practices, and quality of medical care. As a payment reform, ACEs wholly replace much or most malpractice litigation with an insurance system, determining simplified payment amounts for listed events-for example, in obstetrics-without individualized fault-finding. ${ }^{23}$ The new process would resemble the factfinding and decision

23. Because ACEs' payment would occur automatically, without investigations of fault, the approach was initially dubbed "no-fault," see references to "no-fault" in Tancredi, The Analytics of a 
processes of public or private insurance settlement (for non-liability claims). Non-ACE injuries would remain in a case-by-case adjudicatory system, presumably a fault-based one. This residual mechanism could be today's tort regime or some reform alternative. ${ }^{24}$

Other ACE-based reforms leave in place the entire tort system: As a dispute-resolution reform, ACEs are used in conjunction with the current fault system. The ACE listings can assist either (a) pretrial screening or medical review panels or (b) alternative dispute resolution, like arbitration. Knowledge of definitive classes of avoidable injury would be relevant to fault-based dispute resolution, even though ACEs are not themselves fault-based. ${ }^{25}$ As an insurance reform, ACEs help existing liability insurers either to resolve current cases or to manage their insureds' risk, again relying on the listings' informational content. Alternatively, ACE listings can form the basis for a new kind of insurance for medical injury, defining the "insurable event" to be covered. This could occur under first-party, patient-purchased coverage ${ }^{26}$ or medical providers could buy such coverage on behalf of their patients. As a tool for quality reform, ACEs are used only for quality research, monitoring, and feedback by peer reviewers, risk managers, and others. As a statistical basis for monitoring and analyzing bad outcomes, ACEs would be quite congruent with other outcomes-oriented attempts to improve quality of care.

No-Fault System (cited in note 15); Havighurst \& Tancredi, 51 Milbank Mem Fund Q (cited in note 15), thus borrowing for medical care a term popularized for automobile insurance. Alan I. Widiss, et al, No-Fault Automobile Insurance in Action: The Experiences in Massachusetts, Florida, Delaware and Michigan (Oceana, 1977). Unlike auto no-fault, however, which pays for virtually every auto accident, in health care no-fault does not intend to pay for every injury, illness, or death occurring in the course of medical treatment. Such full no-fault would tax the medical system for problems not of its making and would be unduly expensive. Instead, ACEs explicitly focus on preventable classes of injuries. Because of this emphasis, an ACE payment reform could readily be called a "quasi-fault" system. Eligibility for payment is quite selective, but payment itself occurs without regard to individual fault. Hence we have also spoken of ACEs as a "selective no-fault" system. Bovbjerg, Tancredi \& Gaylin, $265 \mathrm{~J}$ Am Med Ass'n 2835 (cited in note 17).

24. One possible case-by-case alternative is an administrative agency to adjudicate medical malpractice, proposed by the American Medical Association and others. See generally Am Med Ass'n, A Proposed Alternative (cited in note 10). Another is mandatory arbitration. Both would supplant conventional tort litigation, but nonetheless would continue to rely on individualized faultfinding through an adversary process.

25. The question arises whether an ACE list would be admissible in court in support of an individualized finding of negligence or to shift the burden of proof in res ipsa fashion. Counting in favor of admissibility would be the relevance of ACEs to good medical practice; counting against would be the fact that factors other than deviation from custom are used to create them. See James A. Henderson, Jr., Use of ACEs Other Than as the Basis of a Compensation System, in Am Bar Ass'n, Feasibility Study (cited in note 10). The issue is similar to that of nonmandatory guidelines for medical practice. See, for example, Eleanor D. Kinney \& Marilyn M. Wilder, Medical Standard Setting in the Current Malpractice Environment: Problems and Possibilities, 22 UC Davis L Rev 421 (1989); Mark A. Hall, The Defensive Effect of Medical Practice Policies in Malpractice Litigation, 54 L \& Contemp Probs 119 (Spring 1991); Clark C. Havighurst, Practice Guidelines as Legal Standards Governing Physician Liability, 54 L \& Contemp Probs 87 (Spring 1991). Whether or not ACE listings would be admissible evidence of negligence, parties negotiating private settlements could find them useful supplements to expert witnesses.

26. First-party insurance would resemble the patient "flight insurance" often discussed in the 1970s. For a 1980s discussion, see Physician Ins Ass'n Am, A Comprehensive Review of Alternatives to the Present System of Resolving Medical Liability Claims 74-77 (Physician Ins Ass'n Am, 1989) ("A Comprehensive Review"). 
Historically, ACEs were invented as a means to effect payment reform, ${ }^{27}$ and this article gives most attention to that prospect. Such reform requires legislation or private contracts to supplant tort law, and would face significant legal challenges, both in legislatures and on judicial review. ${ }^{28}$ However, the ACE concept is potentially also very useful for the "lesser" reforms of dispute resolution, insurance practice, and medical quality assurance-reforms with major potential for improving practice and without major legal hurdles for implementation. Hence, this article deals with the relevance of ACEs to all four types of reform options.

ACEs are very flexible in design and implementation. Therefore, they can be shaped to respond to the advances of medical intervention and to social and economic exigencies of the health care system. Three qualities of ACEs make this flexibility possible. First, ACEs can be calibrated to be broad or narrow for each type of care addressed. The number of adverse outcomes on an ACE list can be altered to meet broader objectives such as social or economic considerations. In addition, the description of the ACE classes can reflect policy objectives. For example, if cost is an issue in the acceptance of a particular ACE, it can be more narrowly described to meet the criteria for inclusion as an ACE and also to assure the economic viability of the health care delivery system. As an illustration, a list of obstetrical ACEs might be limited to the most serious economic injuries, leaving the remainder to the tort system. In this way, ACEs are similar to but far broader than Virginia and Florida's very limited alternative systems for severe "birth-related neurological injury.",29

Second, ACEs can address more or fewer areas of medical care. The ACE approach might be most appropriate in the beginning for surgical episodes involving such specialties as obstetrics and gynecology and general surgery, leaving other care to the existing system or another alternative. Including only a few specialties' care under ACEs allows for practical experience on the implementation of the ACE approach. A replacement system, therefore, can be implemented gradually, monitored for effects, and altered to meet broader social, economic, and medical objectives. Third, ACEs can serve limited purposes within the existing system. This insight lies behind the three nonpayment-oriented reforms noted above.

27. See sources cited in note 15 .

28. See, for example, Blumstein \& Smith, Constitutional Attacks (cited in note 8). On private contracts, see generally Randall R. Bovbjerg \& Clark C. Havighurst, Medical Malpractice: Can the Private Sector Find Relief?, 49 Law \& Contemp Probs 1 (Spring 1986) (entire symposium).

29. Va Code $\$ \$ 38.2-5001$ to -5021 (Michie, Supp 1988); Fla Stat $\$ \$ 766.301$ to 316 (West, Supp 1989). See, for example, Ronald S. Latz, No-Fault Liability and Medical Malpractice: A Viability' Analysis, $10 \mathrm{~J}$ Legal Med 479, 495-96 (1989); James A. Henderson, The Virginia Birth-Related Injury Compensation Act: Limited No-Fault Statutes as Solutions to the "Medical Malpractice Crisis," in Victoria P. Rostow \& Roger J. Bulger, eds, 2 Medical Professional Liability and the Delivery of Obstetrical Care 194 (Nat'l Acad Press, 1989) ("Liability and Obstetrical Care"). 


\section{Pros and Cons of ACE-Based Reforms: Theory}

Using ACEs to find and resolve medical injuries more scientifically has many attractive features. ${ }^{30}$ This section spells them out, and later sections examine them in more detail. First of all, as a payment reform, ACEs promise more widespread and fairer compensation. The listing aids claim detection and helps avoid complicated disputes about responsibility. A simpler, insurancestyle process makes it possible to resolve smaller cases. Standardized rules of damages would be more uniformly applied, making payments more consistent, hence fairer and more predictable. Further, use of an insurance process promises prompt compensation and early rehabilitation. Promptly compensated patients can "get on with their lives." Litigation delays such recovery, ${ }^{31}$ and liability rules perversely give less money to those who have rehabilitated themselves in the interim. In addition, more efficient administration should avoid litigation expenses that are at least twice as high for malpractice as for workers' compensation, and four times higher than for health insurance. ${ }^{32}$ Savings should occur under both payment reforms and dispute resolution reforms.

Moreover, advance, expert determination of objective ACEs will give health professionals greater confidence in the accuracy and faimess of the system, whatever the nature of ACE reform. ACEs' outcomes-orientation and greater acceptance by practitioners should also promote better prevention of medically caused injuries, plus other, longer-run quality advantages: Just creating the list helps focus research and quality control on injury avoidance. ACEs will serve to create a basic framework now insufficiently agreed upon for studying the epidemiology of adverse outcomes and for providing feedback to practitioners. Helpful feedback would include not only the incidence or prevalence of specific ACEs, but also methods for avoiding their occurrence. ACE analysis can also assess the comparative risks of medical intervention in a variety of settings.

30. This section draws heavily on a listing of pros and cons in Bovbjerg, Tancredi \& Gaylin, 265 J Am Med Ass'n at 2837-38 (cited in note 17). Other writing on ACEs or DCEs makes many of these points; see especially Laurence R. Tancredi, Designing a No-Fault Alternative, 49 L \& Contemp Probs 277 (Spring 1986).

31. The median malpractice claim occurs thirteen months after injury and takes a further seventeen or twenty-three months to resolve for unpaid and paid claims respectively, according to a national survey of malpractice claims closed in 1984. US Gen'l Acct'g Office, Medical Malpractice: Characteristics of Claims Closed in 1984, 32-33 (April 1987) (GAO/HRD-87-55) ("Claims Closed in 1984"). Paid claims take longer to close than unpaid, and large claims take longer than smaller claims. Insurers take almost five years to pay out half of their claims dollars for a given year, according to more complete insurance industry statistics compiled by Best's Reproductions of Convention Statements, see Frank A. Sloan, Randall R. Bovbjerg \& Penny Githens. Insuring Medical Malpractice Table 6.1 (Oxford U Press, 1991). Some litigation can take very long indeed. The Government Accounting Office found a range of time from filing to closure of 1 to 132 months; for one published history of an obstetrics case that ran almost twenty-six years, see Jack Dimmer, My Malpractice Ordeal is Over-After Only 26 Years, 66 Medical Economics 50 (October 2, 1989).

32. Randall R. Bovbjerg, et al, Juries and Justice: Are Malpractice and Other Personal Injuries Created Equal?, 54 L \& Contemp Probs 5 (Winter 1991); see also discussion at Part IVB. 
In addition, reductions in nonproductive defensive medicine would occur for three reasons. First, the ACE approach obviates the need for a nonproductive record compiled solely as potential evidence in the event a malpractice claim is made. Second, the ACE system is constructed such that only true prevention can avoid responsibility for an ACE occurrence. Going through the motions is not enough. ${ }^{33}$ Third, ACEs often incorporate positive guidelines to improve care and would encourage further guidelines development. ${ }^{34}$ Improved physician-patient relations should also accompany the shrinking of the current adversary system and its often acrimonious disputes. ${ }^{35}$

As the main quality-oriented payment reform, ACEs have considerable advantages over other so-called no-fault approaches. As the main reform based on predetermined classes of outcomes, ${ }^{36}$ ACEs have considerable advantages over all forms of case-by-case disputation. ACEs are superior not only to litigation but also to alternatives like the American Medical Association plan. ${ }^{37}$ Case-by-case process, especially when fault-based, is inherently more protracted and costly.

Some theoretical objections have been raised about the ACE concept. Critics allege, first, that constructing an ACE list is infeasible on technical grounds. Opponents often assert that ACE lists will be hard to develop and harder yet to apply. ${ }^{38}$ This argument applies to any use of ACEs. It is also objected that little actual "reform" can occur, because so few injuries can be included in any practical ACE list for any type of reform. Thus, any use of

33. Under an ACE-based system, it would remain important to know what procedures were done or omitted, and under what circumstances. Thus, accurate record keeping would be important to evaluating ACEs as it is to good medical care. Moreover, where there is medical consensus or epidemiological evidence of the usefulness of diagnostic procedures, ACEs call for them to be done. However, procedures of little or no medical value would have no usefulness for ACEs, either. However, depending on the extent to which residual tort claims still apply, defensiveness about them could continue to a certain degree. There are reasons to expect overall defensiveness to decline, see discussion at Part IVC.

34. Tancredi \& Bovbjerg, Creating a Selective System (cited in note 13)

35. On the unpleasantness of litigation, especially for medical practitioners, see Bovbjerg, Problems and Solutions at 276-77 (cited in note 9).

36. Virginia and Florida in the last few years have enacted state-run pavment systems for infants severely brain-injured by medical process at birth, see note 29 . but the statutes are so restrictive that as of this writing very few claims have been made under either system.

37. See generally Am Med Ass'n, A Proposed Alternative (cited in note 10); Randall R. Bovbjerg. Reforming a Proposed Tort Reform: Improving on the American Medical Association s Proposed Administrative Tribunal for Medical Malpractice. I Courts. Health Science \& L 19 (July 1990). Yet ACEs are not incompatible with other proposed reforms that seek to remove decisions about medical injury out of litigation. ACE-based payment reform could readily be coupled with additional reform of the caseby-case system needed to handle residual, non-ACE cases. See note 24 and accompanying text.

38. Historically, the first objection was that medically caused injuries simply cannot be separated * from risks of underlying conditions. David S. Rubsamen, No-Faull Liability for .tduerse .Medical Events, 117 California Med 78, 78 (1972); Robert E. Keeton. Compensation for Medical Accidents, 121 U Pa I. Rev 590, 594 (1973). Subsequently, other commentators made the related claim that any feasible listing would be very difficult to effectuate. William B. Schwarty \& Neil K. Komesar, Doctors, Damages, and Deterrence, 298 New Eng J Med 1282. 1282 (1978); Guido Calabresi, The Problem of Valpractice: Trying to Round Out the Circle and Richard A. Epstein. Medical Malpractice: Its Cause and Cure, both in Simon Rottenberg, ed, The Economics of Medical . Malpractice 233 and 245 respectively (Am Enterprise Inst, 1978). 
ACEs will leave almost all of the current system unchanged. ${ }^{39}$ A third criticism is that few savings on administration are possible. The ACEs that would be removed from the tort system under any payment-system reform are (by definition) avoidable injuries, in which liability is usually obvious. Hence, ACEs are (by hypothesis) now quickly and inexpensively resolved through informal insurance settlement, without costly litigation or trial. ${ }^{40}$ Finally, and contrary to the second objection, it is argued that a huge increase in cases will result from any "no-fault" system of coverage. This increase, critics say, will make any new ACE payment system impractically expensive. ${ }^{41}$

\section{IV}

\section{The Likely Performance of Aces: Evidence and Discussion}

Over the course of almost two decades of ACE development, research has addressed and resolved many questions about these potential pros and cons of ACEs. This section discusses what is known and unknown about ACEs' likely performance-mainly from the perspective of payment reform, but ending with an extended discussion of ACEs as a quality reform.

\section{A. Arguments Against ACEs}

Consider first the arguments against ACEs, largely raised against their use as a payment reform to replace the tort system for many injuries. The earliest and most basic objections of infeasibility have been most thoroughly laid to rest. Only the "first generation" of largely conceptual research left much doubt that ACEs are a practical alternative. ${ }^{42}$ Subsequent work has made clear that experts can readily agree on avoidable adverse outcomes for listing, certainly in surgery and in obstetrics/gynecology. ${ }^{43}$ Moreover, the listings have been successfully applied in practice to both medical and insurance data on injuries. ${ }^{44}$

39. Patricia M. Danzon, Medical Malpractice: Theory, Evidence, and Public Policy $214-17$ (Harvard U Press, 1985).

40. Id at 214 .

41. This is a long-standing argument with regard to full no-fault coverage. See, for example, David Mechanic, Some Social Aspects of the Medical Malpractice Dilemma, 1975 Duke L J 1179, 1193-94. It was first empirically supported by Mills, Boyden \& Rubsamen, Report on the Feasibility Study (cited in not a 5), specifically dealing only with broader no-fault, however. For more explicit attacks on selective no-fault, see Patricia M. Danzon, Medical Malpractice Liability, in Robert E. Litan \& Clifford Winston, eds, Liability: Perspectives and Policy 101 (Brookings Institution, 1988); Am Med Ass'n, A Proposed Alternative (cited in note 10); Carter G. Phillips \& Elizabeth H. Esty, A Fault-Based Administrative Alternative for Resolving Medical Malpractice Claims: The AMA-Specialty Society Medical Liability Project's Proposal and Its Relevance to the Crisis in Obstetrics, in Rostow \& Bulger, eds, Liability and Obstetrical Care at 136, 138-40 (cited in note 29).

42. See sources cited in note 15 .

43. The American Bar Association Commission reached this conclusion over ten years ago with regard to orthopedic and general surgery. See Am Bar Ass'n, Feasibility Study at 5 (cited in note 10). So has at least one more recent review, Latz, $10 \mathrm{~J}$ Legal Med at 495 (cited in note 29).

44. The authors have applied ACE listings in several relevant contexts. See, for example, Boyden \& Tancredi, Identification of DCEs at 21-22 (cited in note 16) (mid-1970s closed-surgical claims data from the compilation made by the National Association of Insurance Commissioners); see also M. Patricia Sowka, ed, NAIC Malpractice Claims: Medical Malpractice Closed Claims 1975-1978 (Nat'l 
Nor are opponents correct that ACE listings can include only a few obvious injuries. It is true that the most obvious outcomes, ones that could be res ipsa cases, are included, but the list goes well beyond that. As Table 1 showed, ACEs encompass quite a broad spectrum of cases, including problems of both commission and omission. Inclusion of a number of omissions as ACEs is one way that the third-generation lists have advanced over early conceptualization. ${ }^{45}$ Thus, ACEs should logically apply to many or most current malpractice claims. This expectation is borne out by the only detailed ACE analysis of liability claims information:46 for obstetrics, ACEs appear to cover at least half of current tort claims. Moreover, also contrary to the prior arguments of critics, the ACEs disproportionately included major injuries: among ACEs were two-thirds of the permanent serious injuries, comprising about three-fourths of the indemnity paid in tort. ${ }^{47}$

ACE opponents also seem wrong in assuming that the current tort system easily resolves ACEs. Obstetric ACE injuries in fact took somewhat longer to settle in tort than did non-ACEs, and their defense cost much more per case. $^{48}$ Such delay is consistent with having more consequential injuries, which are slow and expensive to resolve under the current tort system. At least for obstetrics, it therefore appears that great savings on time and expense of administration are feasible, contrary to ACE opponents' intuition that ACEs should settle readily, even in tort. ${ }^{49}$

Ass'n of Ins Commissioners, 1980) ("NAIC Malpractice Claims"); Bovbjerg, Tancredi \& Gaylin, $265 \mathrm{~J}$ Am Med Ass'n at 2838-43 (cited in note 17) (closed obstetrical claims files); Randall R. Bovbjerg, et al, Finding Medical Injuries in Medical Records: Applying Lists of Avoidable Bad Outcomes to Medicare Hospitalizations (submitted for publication 1991) (hospital records on Medicare surgical admissions) ("Finding Medical Injuries").

45. Mills, Boyden \& Rubsamen, for example, commented on how the first generation of selective no-fault focused almost entirely on problems of commission. Mills, Boyden \& Rubsamen, Report on the Feasibility Study at 3-5 (cited in note 5), citing Havighurst, 1975 Duke L J at 1233-80 (cited in note 15 ).

46. This information comes from our investigation of how obstetric ACEs would work in practice, Bovbjerg. Tancredi \& Gaylin, $265 \mathrm{~J}$ Am Med Ass'n (cited in note 17). We studied a population of over 300 obstetrical malpractice claims files, all those closed during $1983-89$ within a large, national, self-insured hospital chain. Claims files originating in twenty-three U.S. states and the District of Columbia were included, and mothers' races and ages resembled national norms. So the population studied seems representative. The ACE listing was applied by trained nurse-claims abstractors, who also noted demographic data pertaining to the injury and economic information.

47. Id at 2839. Large-dollar cases predominated among obstetric ACEs. In part, ACEs' higher levels of severity occur by design. For reasons of maintaining objectivity, the definition of ACEs builds in a minimum threshold of significance, below which medical causation and avoidability become muddled. See Boyden \& Tancredi, Identification of DCEs at 28 (cited in note 16); Tancredi \& Bovbjerg, Creating a Selective System (cited in note 13). In our analysis of sampled Medicare hospitalizations, about half the injuries located were ACEs and they did not differ in severity from non-ACEs, see Bovbjerg, et al, Finding Medical Injuries (cited in note 44) (but noting problem generalizing to entire universe of Medicare).

48. ACEs composed about $44 \%$ of non-litigated cases, some $66 \%$ of cases where suit or arbitration was begun, and all four of the observed trials. Defense costs averaged $\$ 21,000$ per ACE case, as compared to $\$ 6,000$ for non-ACE cases. See Bovbjerg, Tancredi \& Gaylin, $265 \mathrm{~J}$ Am Med Ass'n at 2839 (cited in note 17); see also discussion at Part IVB2.

49. This finding for obstetrics cases from one reasonably large and representative set of claims needs to be replicated elsewhere. According to a colleague, ACE-like cases in Florida appear to settle short of a trial more often than other cases. Personal communication from Frank A. Sloan, 


\section{B. ACEs and Cost}

Would any ACE-based alternative payment system for medical injuries cover so many claims as to make its costs politically infeasible? The contention that it would is the last and most important objection. Note first that opponents rely mainly on theoretical arguments rather than empirical evidence. No one has yet applied any ACE listing to a full set of information on medical injuries, in part because good, population-based research on injuries is extremely rare. ${ }^{50}$ Because direct evidence is lacking, a more complex, indirect analysis is needed.

1. The Extent of Medical Injury and Medical Litigation. The initial concern about any "no-fault" system in medicine is that so many bad outcomes occur naturally, regardless of medical intervention. ${ }^{51}$ For one thing, natural deaths most often occur in hospitals. The subset of bad outcomes that are medically caused is much smaller, as is the further subset that are due to medical negligence. Yet even the limited category of negligent medical injury seems to contain far more cases than currently appear in the tort system. The main evidence here comes from reviews of hospital medical records, first for California in $1974,{ }^{52}$ most recently for New York in $1984 .{ }^{53}$ Some 4 to 5 percent of hospital charts show evidence of a medically caused injury, and about 1 percent of the total show negligent injury-seemingly a low proportion. When applied to the large number of hospitalizations, however, one percent works out to eight or ten times more cases than the corresponding number of malpractice claims made. ${ }^{54}$ This failure to deal with

Vanderbilt University, October 1990. Some risk managers also report that they try to settle ACE-like cases quickly.

50. The authors have collaborated with researchers elsewhere to seek funding to apply ACEs to information on medical injuries in New York hospitalizations during 1984. These data were compiled by the Harvard Medical Practice Study, Patients, Doctors, and Lawyers (cited in note 5), and comprise the only known broad-based and current data base on such injuries. Bovbjerg, et al, Finding Medical Injuries (cited in note 44), also examined hospital injuries from the perspective of avoidability, but lacked a generalizable sample.

51. See sources cited in note 38 .

52. Mills, Boyden \& Rubsamen, Report on the Feasibility Study (cited in note 5).

53. Harvard Medical Practice Study, Patients, Doctors, and Lawyers (cited in note 5).

54. Don Harper Mills has long pointed out that for California in 1974, the estimated number of actual negligent injuries found in hospital charts outnumbered that year's meritorious malpractice lawsuits by about ten or more to one. See, for example, Don Harper Mills, Comments on Where We Stand and What We Know, presented at an Urban Institute conference, Medical Malpractice: Can the Private Sector Find Relief, Washington, D.C. (February 21, 1985). Patricia Danzon published a similar calculation in her October 1985 book. Danzon, Medical Malpractice at 20-25 (cited in note 39). She estimated a 1974 ratio of 1:10 for all claims to negligent injuries and 1:25 for paid claims to injuries (comparing the estimate made by Mills, Boyden \& Rubsamen, Report on the Feasibility Study at 98-101 (cited in note 5), with the NAIC aggregate insurance data from 1975 to 1978, Sowka, ed, NAIC Malpractice Claims at 6 (cited in note 44). These rough estimates did not match years of injury occurrence or account for injuries not discoverable in hospital records.

The New York Study made a more refined comparison, matching individuals in 1984 with corresponding insurance claims records for 1984 incidents. This process found a ratio of all claims to negligent injuries of between 1:7 and 1:9. Harvard Medical Practice Study, Patients, Doctors, and Lawyers at 7-24 to 7-41, especially Table 7.7 (cited in note 5). For the study's critique of Danzon, see id at 7-2 to 7-5. The study also found that most of the malpractice claims involved hospital 
most negligent injury is one of the major weaknesses of the current system, for purposes of both compensation and deterrence, as already noted.

It is not known with certainty why so many cases of negligent injury are not brought as claims or lawsuits. Presumably, some incidents go unrecognized as negligence. Some patients do not need tort compensation (especially for minor injuries already compensated by health and disability coverage ${ }^{55}$ ), or are not litigious. And some cases are not worth the high costs of tort process (especially minor injuries and marginally provable claims ${ }^{56}$ ). In any case, the hospital injury studies make clear that a full no-fault plan would cover far more injuries than are discovered and brought under today's fault system.

Accordingly, the California study concluded that full no-fault was unaffordable, but its authors specifically noted that they were not assessing a selective system, ${ }^{57}$ like ACEs. The New York study concluded that a limited, "catastrophic" version of no-fault (limited to disabilities over six months duration and secondary to all other payers) would cost about the same as the current fault system. ${ }^{58}$ Of course, for any alternative system, the estimation of additional costs and savings necessarily must go far beyond the simple question of number of cases to consider the amount of payment per case, as well as administrative costs.

2. Specific Costs Under ACEs. What evidence exists on ACEs? It is helpful to consider the various costs and savings likely under ACEs, as systematically set forth in Table 2. The first of two new dollar costs is that of ACE cases already discovered and brought as tort claims, but not now paid under the tort system. The only available evidence here relates to obstetrics claims. For one major hospital chain, 35 percent of obstetric ACEs already receive payment under the tort system, ${ }^{59}$ so that any new ACE payment system would have to cover the 65 percent not now paid. However, these "unpaid" ACEs generally involve much less severe injuries, conservatively estimated to cost less than 30 percent as much per case. ${ }^{60}$ So the net cost would rise by only about half,

admissions whose records had not been found to involve negligent injury as defined by the study protocol. Id at 7-36 to 7-37.

55. Injury and claims data suggest that more severe injuries are more likely to be brought as claims. Recall that California hospital claims for 1974 were only $10 \%$ as numerous as negligent hospital injuries, see notes 51-54 and accompanying text. For three categories of temporary injury, however, the ratio was only $6-8 \%$, whereas for four categories of permanent injury, it was $11-17 \%$. For death, it was 6\%. Danzon, Medical Malpractice at 23, Table 2.4 (cited in note 39).

56. One instructive piece of evidence here is that death cases seem the least likely of all to be brought as claims; there are only $5.8 \%$ as many claims as negligent deaths. See, for example, id. This suggests either lack of need (for example, no ongoing medical expenses and likely cash death benefits available) or low legal benefit/cost ratio (for example, restrictive legal rules on wrongful death and survivorship claims).

57. Mills, Boyden \& Rubsamen, Report on the Feasibility Study at 5 (cited in note 5).

58. Harvard Medical Practice Study, Patients, Doctors, and Lawyers at ch 8, 8-79 (cited in note 5).

59. The $35 \%$ ACE success rate may seem low, given that our expert consultants rated all ACEs as at least $70 \%$ avoidable. We note in passing that an even lower $18 \%$ of non-ACEs received any tort compensation. This disparity is evidence that the tort system, far from being random or pernicious, effectively comports with epidemiological notions of avoidable injury.

60. The unpaid ACEs are estimated to be worth the same amount, under current rules of damages, as paid ACEs of the same severity of injury, as scored on an objective nine-point scale. 
even assuming ACEs were paid at tort-system valuations of loss. ${ }^{61}$ Moreover, there are indications that this increase would be less elsewhere than in the hospital obstetric claims that provided this estimate.

TABLE 2

Costs and Savings under an ACE Payment Reform

\begin{tabular}{lll}
\hline FISCAL IMPACT & Item & Comments \\
\hline
\end{tabular}

DOLLAR COSTS

Injuries not now paid that receive payment as ACEs:

(a) Unpaid ACEs now in system

(b) New cases brought in ACE system

OB study shows small dollars here because smaller cases

Must estimate "inducement" factor, likely to be disproportionately small cases

\section{DOLLAR SAVINGS}

Fewer cases:

Fewer injuries, hence ACE cases, in long run

Savings come from improved quality, better deterrence

Lower indemnities:

(a) I ower losses per case because of earlier intervention \& rehabilitation

(b) Less non-pecuniary loss allowed for ACEs

(c) "Scheduled" economic loss for ACEs, other economizing rules

This is a key attribute of accelerated ACE payment and avoidance of fault finding; exact extent imponderable

Clear savings available; can only estimate extent

Presumably savings available; again, indeterminate

Lower expenses:

(a) "Defense" side of ACEs

(b) Claimant side of ACEs

Substantial savings almost certain, can be estimated in various ways

Presumably similar to defense side; dollars directly saved through changes in damage rules

Other savings:

"Defensive medicine" curtailed under ACEs

Effect has value beyond the monetary; precise monetary extent uncertain; unclear current defensiveness \& likely cutbacks

\section{DOLLARS UNCHANGED}

Non-ACE cases remaining in the tort system or other alternative

Numbers brought and amounts obtained might stay the same, but might also drop

The second, and more problematic, new dollar cost is that of new cases "induced" to be brought by the existence of an easier, faster, less unpleasant system (but one paying less per successful claimant). The fear traditionally

Unpaid ACEs then have an average imputed value of under $\$ 200,000$ per case, as compared to more than $\$ 700,000$ for paid ACEs. This estimate is conservative because more severe injuries are more likely to be paid than less severe ones, so that unpaid ACEs may tend to be in the lower end of their injury category.

61. Under ACEs, however, it is expected that damages will be more controlled. See discussion at notes 107 to 114 . 
expressed is that new cases not now pursued as claims could "come out of the woodwork" in unmanageable numbers. Undeniably, ACEs used for payment reform would expand compensation to some extent. That is a major goal of reform. Just promulgating a list should make injuries easier to recognize as compensable; how much easier can only be estimated. Many have argued that "no-fault" would unacceptably raise claims frequency. ${ }^{62}$ Clearly, full "nofault" would greatly expand coverage. But on its face the criticism is far less valid for ACEs, which are not part of the comprehensive system of social insurance but rather a limited extension of the ability to collect for preventable medical injuries.

Just how many cases would appear under ACEs? On the strength of this inducement effect, there is only indirect evidence. ${ }^{63}$ Our data on obstetric ACEs by stage of resolution are relevant to this issue. The instructive bits of evidence from this study involve cases now brought, not by requests for payment from injured patients or their lawyers, but rather by medical providers or risk managers. Consider the cases opened without a formal claim and closed before the start of any legal process. Such "preclaim" cases are not well represented in some claims studies, ${ }^{64}$ and they most closely resemble the "unbrought" cases of concern here. Among ACEs, the ratio of formal claims to preclaim cases (about 4:3) is higher than among non-ACEs (1:1). Thus, claimants seem somewhat more likely to find ACEs than nonACEs, and it is plausible that fewer ACEs go unfound by the current system than do non-ACEs. Looked at in another way, claimants found a higher share of ACEs relative to those reported only by medical professionals than claimants did of non-ACEs. This finding suggests that ACEs are indeed more readily recognizable than liability cases in general. However, additional work would strengthen this finding, especially to address the suspicion that many potential claims of all kinds are not found. ${ }^{65}$

62. Mills, $128 \mathrm{~W}$ J Med at 260 (cited in note 5); Danzon, Medical Malpractice at 213-19 (cited in note 39 ).

63. The best answer would come from a survey of medical care, not a survey of liability claims like the obstetric data discussed in text. There is little such evidence, and the authors are assisting in a broad-based study of medical outcomes, using New York hospital data, see Harvard Medical Practice Study, Patients, Doctors, and Lawyers (cited in note 5); our narrower study of selected Medicare hospitalizations could not illuminate this issue, see Bovbjerg, et al, Finding Medical Injunies (cited in note 44). In the meantime, a reasonable upper-bound estimate of ACE incidence is the excess of negligent injuries from the hospital studies over corresponding liability claims. The eight- or ten-toone ratio of injuries to claims seems overdone, as ACEs seem to consist of generally more severe injuries, for which the ratio is lower, as is discussed in footnotes 66-68.

64. For example, US Gen'l Acct'g Office, Claims Closed in 1984 at 15 (cited in note 31) ("claim" does not include cases for which no formal demand for payment was made by any claimant). The General Accounting Office had to limit its definition to make "claims" consistent across the numerous insurers in its study.

65. In one sense, the preclaim reports should capture much of the medical injury that does not now become formal claims. Medical professionals are encouraged to report even potential cases, by their hospitals for quality reasons and by their insurers for liability and risk management reasons. Further, they can do so without instigating a lawsuit. However, most risk managers feel that too few significant outcomes are in fact reported, see Orley $\mathrm{H}$. Lindgren, Ronald Christensen \& Don Harper Mills, Medical Malpractice Risk Management Early Warning Systems, 54 L \& Contemp Probs 23, 25 (Spring 1991); Laura L. Morlock \& Faye E. Malitz, Do Hospital Risk Management Programs Make a Difference?: 
There are also indications that "unbrought" cases disproportionately involve less serious injuries. In our obstetrics study, the preclaim ACEs (and non-ACEs) involved less severe injuries than those in which a formal claim was brought. ${ }^{66}$ This pattern is consistent with earlier findings ${ }^{67}$ and with expectations about the severity of unbrought cases: clearly, claimants have more incentive to notice an injury that has large physical and economic consequences and to consult an attorney about bringing a claim. Moreover, we found that more severe obstetric injuries were disproportionately likely to receive payment ${ }^{68}$ - which also currently gives large cases more reason to be brought than small cases. Thus, there are reasons to believe that the new cases under an ACE system can be expected to be disproportionately less serious cases, so that an ACE payment system would not be inundated with large new claims.

Empirically, we conclude that the "inducement" objection is at best overstated, but this conclusion is tentative. We also suspect that the inducement effect will vary with circumstances. It is logical, for instance, to expect obstetric ACEs not to provoke as many new claims because "bad babies" now are easier for lay people to recognize than are other bad outcomes. As obstetricians often complain, having less than a perfect baby can readily raise parents' suspicions, although clearly not all sue, contrary to the more expansive claims of the medical fraternity.

To conclude the discussion of induced increases in claims frequency, consider three qualitative observations. First, an ACE payment system intentionally seeks to broaden compensation. ACEs are meant to reach those injuries that are logically the responsibility of the medical system, as the current system so drastically fails to do. Second, it is unreasonable to compare the cost of an ACE-based payment reform only to the cost of today's liability system. The current tort system may not be bearing the cost of the numerous negligent or avoidable injuries not now brought as claims. But someone is, whether an insurer like Blue Cross or Social Security or the individual injured person and his or her family. To the extent that ACEs bring this cost within the ambit of medical responsibility, they are shifting an existing cost, not creating a new one. That is, any increase in ACE versus

Relationships Between Risk Management Program Activities and Hospital Malpractice Claims Experience, 54 L \& Contemp Probs 1, 5-6 (Spring 1991), so we lack confidence that the preclaim cases discussed in text represent most medical injuries.

66. Most preclaim obstetric cases were temporary injuries, most postclaim ones permanent. Bovbjerg. Tancredi \& Gaylin, $265 \mathrm{~J} \mathrm{Am} \mathrm{Med} \mathrm{Ass} \mathrm{n}$ at 2839 (cited in note 17).

67. See Danzon, Medical Malpractice at 22-25 (cited in note 39). Nonetheless, although cases of permanent injury, for example, are more likely to appear as claims today, such claims are still outnumbered by nonclaims, by a margin of almost $6: 1$ (less than the overall 10:1). See id at 21,23 , Tables 2.1, 2.4.

68. Bovbjerg, Tancredi \& Gaylin, 265 J Am Med Ass'n (cited in note 17). This corroborates the findings of the General Accounting Office. See US Gen'l Acct'g Office, Claims Closed in 1984 at 41 , Table 3.3 (cited in note 31 ). 
liability spending is matched by an equal and opposite decrease in someone else's non-liability spending. ${ }^{69}$

Third, any bulge in claims under ACE coverage would be temporary: a proper assessment needs to consider, not just any one-time increase in the flow of claims through a changed insurance system, but also the dynamic of any future changes. Despite temporary lulls, the history of the tort system has been one of inexorable expansion. ${ }^{70}$ Likewise, other systematic compensation reforms, such as workers' compensation and the New Zealand plan, have also been characterized by continuing expansion of those adverse outcomes that are automatically compensated by these systems. ${ }^{71}$ In disputes, payers tend to prefer to compensate injuries, rather than to refuse to do so and create additional administrative expenses. ${ }^{72}$ In contrast, under the ACE system, inclusion of adverse outcomes is professionally determined. Medical providers evaluate the relative avoidability of adverse outcomes from an epidemiological perspective, under which constraints on expansion are built in. Professional criteria and oversight limit inclusion on ACE lists, even in those cases involving boundary issues.

3. Specific Offsetting Savings Under ACEs. The costs just noted need to be offset by the likely savings under ACEs noted in Table 2. For a start, instituting an ACE-based payment or quality reform will in the long run tend to reduce the number of cases, by reducing the number of injuries. This prediction is necessarily unproven at this point, but follows logically from ACEs' likely quality incentives, discussed below. ${ }^{73}$

Next, in several ways, an ACE payment reform should reduce indemnities paid per case. ACEs are designed to encourage new, faster medical intervention and dollar payments to support non-medical needs, such as wage replacement, education, homemaker services, and transportation. This should speed rehabilitation and, hence, save money. Savings should also accrue from changes in payment rules and process, such as limited payments for pain and suffering, specified offsets for the nontaxable nature of insurance

69. It is not intended that an ACE system allow double recovery for the same loss. Either there should be collateral source offset for ACEs or collateral sources should be notified and allowed subrogation-or some mix of payment responsibility should be set. See Havighurst \& Tancredi, 51 Milbank Mem Fund $Q$ at $152-56$ (cited in note 15). The observation is not new that someone bears the cost of injury, no matter whether or how it is compensated. Compare Guido Calabresi, The Cost of Accidents (Yale U Press, 1970) (key social goal in assigning responsibility is to minimize cost of accident plus cost of accident avoidance). However, when an injury is moved into the tort system, costs rise considerably; a large share of tort costs consists of a monetization of nonpecuniary injury ordinarily borne only in nonfiscal form, and the system also imposes extremely high carrying charges of investigation and litigation. The same should not be true for an ACE-based system.

70. See, for example, Priest, 96 Yale L J at 1521 (cited in note 1).

71. A. P. Blair, Accident Compensation in New Zealand: The Lau Relating to Compensation for Personal Injun by Acrident in . Vew Zealand (Butterworths of New Zealand, 2d ed 1983); Geoffrey W.R. Palmer, Compensation for Incapacity: A Study of Law and Social Change in New Zealand and Australia (Oxford U Press, 1979).

72. Remarks of Patricia M. Danzon, Robert Wood Johnson Foundation Annual Meeting on Medical Malpractice Project (Washington D.C., October 1990).

73. Sec Part IVC. 
payments, regularized calculation of present value of future losses or use of periodic payments, and the like. ${ }^{74}$ The exact extent of potential savings is uncertain, but surely it is rather large compared with allowances under current rules of damages, especially for nonpecuniary losses. ${ }^{75}$

Another likely economy under ACEs is lower expenses per case on claims administration and litigation. The cost of defending claims will fall considerably under ACEs. Malpractice litigation is expensive on both sides, even where cases do not go to trial. ${ }^{76}$ On the defense side, for example, our obstetrics claims data showed an average defense cost (technically, "allocated loss expense" or payments to outside lawyers and investigators) of about $\$ 50,000$ per paid ACE case, and $\$ 21,000$ per case for all ACEs (paid and unpaid). ${ }^{77}$ These ACE amounts were about triple those for resolving nonACEs (some $\$ 18,000$ and $\$ 6,000$ respectively, for paid and unpaid cases). ${ }^{78}$ How much could be saved under an ACE system where all defendants would be under one insurance reckoning? Perhaps the expense per paid obstetric case would be reduced to that of currently unpaid ACEs (or about $\$ 5,000$ ); perhaps the cost would fall further, to about the level of non-litigated cases in our data, or about $\$ 1,100$ each. In any case, savings would be substantial.

Aliernatively, consider how liability insurance costs compare with other insurance costs. All together, obstetric cases in our study averaged 17 percent of indemnity for allocated loss expense. Industry-wide data for medical malpractice insurance show an even larger rate-averaging 33 percent for 1980-85, and rising to 43 percent for $1988 .{ }^{79}$ In stark contrast, the

74. See discussion of damages at notes 107-14.

75. On the large role played by nonpecuniary losses, see generally Randall R. Bovbjerg, Frank A. Sloan \& James F. Blumstein, Valuing Life and Limb in Tort: Scheduling "Pain and Suffering, " $83 \mathrm{Nw} \mathrm{U} \mathrm{L}$ Rev 908 (1989). It is hard to calculate the non-pecuniary losses involved in any single claim. Claims adjusters settle entire injuries as a lump sum and do not indicate just what amounts are allowed for different elements of loss. Conventionally, analysts subtract dollar losses written in the record from the total payment (including present value of periodic payments). However, this does not allow for the fact that settlement bargaining normally discounts claims values in various ways. For these reasons, our obstetric ACE study did not attempt to compute economic versus nonpecuniary losses, even though we had access to actual claims files.

For data using the conventional approach, see US Gen'l Acct'g Office, Claims Closed in 1984 at 45. Table 3.6 (cited in note 31 ) (showing positive nonpecuniary losses paid up to economic loss level of $\$ 100,000$, but negative above that level-for example, for economic loss of $\$ 1$ million and more, average indemnity was $\$ 439,000$ ).

Another way to estimate savings on nonpecuniary losses is to consider that such damages are commonly assumed to pay plaintiffs' lawyers' fees. On savings there, see notes $81-82$ and accompanying text.

76. See also Thomas B. Metzloff, Resolving Malpractice Disputes: Imaging the Jury's Shadow, 54 L \& Contemp Probs 43, 53-59 (Winter 1991).

77. Bovbjerg, Tancredi \& Gaylin, $265 \mathrm{~J}$ Am Med Ass'n at 2840 (cited in note 17).

78. Id.

79. Bovbjerg, et al, 54 L. \& Contemp Probs at 5 (cited in note 32). The loading just for ACEs is lower (presumably because their indemnities are relatively high)-“only" $14 \%$. Although the dollar cost of settling ACEs is much higher per case than for non-ACEs, the percentage is lower, because ACE indemnities are so very high relative to non-ACEs (a ratio of 7.6:1-an even greater disparity than the difference in average expense of $3.5: 1$ ). However, opponents of the ACE concept can take no comfort from this observation, for the ACE percentage is lower only because ACE indemnities are so high, and the relevant figure for considering potential savings from more efficient claims resolution is the much higher absolute number of dollars not spent on resolving ACEs. 
comparable rate for workers' compensation insurance is about 11 percent; for group health insurance, about 5 percent. ${ }^{80}$ Additional savings could be expected in other insurance costs, like general overhead, but we have no direct way to estimate them.

On the claimants' side of the ledger, large savings can be expected in the contingent fee and legal expenses a claimant must pay a lawyer out of an award. A typical fee for most states is 33 percent. In some states, malpractice fees are limited by a sliding fee that declines with the size of the award, to a marginal percentage as low as 10 percent (as in California for portions of awards above $\$ 200,000$ ). ${ }^{81}$ Under ACEs, if a claimant used a lawyer at all, the fee could be expected to be far lower, perhaps the 15 percent allowed in Indiana for the no-fault recovery there in large cases from the Patient Compensation Fund ${ }^{82}$ or the lower fees associated with workers' compensation cases. Thus a substantial savings seems readily achievable here.

Another source of savings is cutbacks in defensive medicine, that is, extra tests and procedures ordered more for legal defense than for medical efficacy. Under ACEs, doctors and hospitals should be able to achieve cutbacks on such spending-if patients and payers successfully insist on them once legal pressures are reduced by ACEs. ${ }^{83}$

Finally, Table 2 notes a general presumption that those cases not reformed will not change in any way. That is, non-ACE injuries will not increase or decrease in number or in size of damage payments. In reality, expecting a dynamic shift seems more reasonable. Some might argue that lawyers will greedily bring new fault cases to make up for the old ones lost. This simplistic view seems highly improbable: ACEs will not make residual fault cases easier to prove or more profitable for lawyers to bring. If any type of case is profitable for lawyers to bring after ACEs, then it must also be profitable now as well, so it is probably already being pursued-or is likely soon to be pursued as the tort system continues to expand.

Instead, the most likely dynamic effect would cut the other way: ACEs may well make residual fault claims harder to win because of subtle cultural shifts in attitudes about medicine and fault. Once an ACE system is implemented and generally appreciated, claimants, lawyers, judges, and jurors are likely to understand that obvious problem cases are no longer in the tort system. Given such attitudinal shifts, a new de facto presumption about medical causation and responsibility will arise that could make tort claims harder to prosecute, even without de jure change. This prediction of savings is not certain, but is certainly more reasonable than the contrary expectation of higher residual tort costs.

80. Id.

81. Calif Bus \& Profess Code $\S 6146$ (1987).

82. Eleanor D. Kinney \& William P. Gronfein, Indiana's Malpractice System: No-Fault by Accident?, 54 L \& Contemp Probs 169. 174 (Winter 1991).

83. On reduced incentives for defensiveness, see text accompanying notes 33-35 and Part IVC. 


\section{Advantages of ACEs}

Having canvassed evidence on the alleged disadvantages of ACEs, we return briefly to their advantages. Most of the advantages listed above fit within the three main categories of better compensation (broader-based, more even-handed, faster); better process (cheaper to administer, faster, less unpleasant, and less subject to abuse); and better prevention of injury or deterrence (because of being professionally generated, with an outcomes orientation and greater medical credibility). ${ }^{84}$ Evidence on the likely comparative cost and speed advantages of ACEs was presented immediately above in Parts IVB2 and 3 in countering objections of high cost.

The other advantages necessarily remain a matter of theorizing rather than empirical documentation so long as ACE processes exists only in theory. But we repeat that the advantages make logical sense. ${ }^{85}$ An actual, operational "field test" is needed to demonstrate many of ACE systems' positive attributes for payment reform in practice. Ultimately, operational testing is also needed to consider effects of ACEs as a quality reform, to which we turn next.

1. Quality Reform: ACEs, Practice Guidelines, and Defensive Medicine. In the long run, the greatest benefit of ACEs may be as a quality measure. After all, the best response to medical injury is to prevent it, not to compensate it after it occurs. ${ }^{86}$ ACE-based systems' quality improvements may come as an adjunct to payment reform, as insured institutions or specialties respond to new fiscal responsibilities with new efforts at quality control. Alternatively, ACEs could be implemented as a separate reform of quality only, with no direct impact on the tort system's resolution of injuries. Either way, ACEs could be implemented institution by institution, state by state, or, conceivably, at the federal level. ${ }^{87}$

The main point is that ACEs are an outcomes-oriented, systematic way of ordering practitioners' responses to low-quality outcomes of care. In many respects, ACE development resembles the burgeoning movements for medical outcomes assessment ${ }^{88}$ and practice guide-

84. See generally Part IVC.

85. For example, it is completely logical that an insurance-style ACE-based payment system could resolve cases faster than the current system. The existence of an ACE list would facilitate prompt discovery of injuries to begin with. Thereafter, there would be no need for the extraordinarily detailed fault-finding of the current system. The calculation of damages would also be simplified. Moreover, pavments could begin immediately because providers would not fear thereby admitting liability as they now do. All this would encourage prompt discovery of injury and early intervention-which should reduce the extent of harm actually incurred, especially in the very serious cases of permanent injury that account for the bulk of today's indemnity.

86. This point assumes that prevention is not unduly costly.

87. To assume that payment reform could occur institution by institution is to assume special enabling legislation or to accept that tort reform can be accomplished by private contract, as urged by Professors Epstein and Havighurst, among others. See Bovbjerg \& Havighurst, 49 L \& Contemp Probs 1 (cited in note 28) (symposium).

88. See, for example, 9 Health Care Financing Review Annual Supplement (1987) (symposium issue). ACEs are not unlike outcome measures sought for quality purposes. See generally Paul $\mathbf{S}$. 
lines. ${ }^{89}$ A key difference is that ACEs are generated within an organized framework of very focused, practical, and ongoing outcomes monitoring. If quality reform is part of payment reform as well, the need to determine fiscal responsibility will also help focus attention and motivate compliance. ACEs will both promote quality and reduce defensiveness.

2. Promotion of Quality. The ACE approach focuses attention on outcomes and also provides a framework for assessing and encouraging quality care in medical practice. Its systematic listing of avoidable classes of outcomes makes professionals think in terms of statistical outcomes on a continuing basis, not just for one-time research on quality of care. Such lists can be used to monitor the incidence and prevalence of adverse outcomes in health care institutions and private clinical practice, and thereby provide a basis for comparison among providers of care. ACEs would both identify problem areas of practice and, unlike research or even guidelines alone, would create incentives to rectify these problems.

Many ACEs give positive guidance about appropriate care, thus incorporating a kind of guideline. This is especially true for those ACEs that include elements of procedures in their definition, identifying general patterns of practice that should be followed or averted. Most of these cover problems of omission rather than commission. For example, the following ACE for orthopedic surgery incorporates a procedure and explicitly refers to lowquality medical intervention that induces untoward outcomes: "Wound infection from failure to treat a compound fracture with antibiotics." The desirability of treating with antibiotics is clear.

In other cases, ACEs will strongly encourage the development of guidelines. For all ACEs, the implication of a sub-quality procedure is clear, at least when compared to the statistical aggregate (the putative norm) of similar interventions. The patterns of ACE occurrences will help determine what particular practices are associated with high and low incidence and thereby encourage adoption as guidelines of practices found to be superior.

The following ACE illustrates the point: "Spinal cord paralysis secondary to any anterior cervical discectomy." If a proper anterior cervical discectomy had been performed-which would include those procedures associated with the preparation of the patient (such as proper diagnostic measures) - spinal cord paralysis would have been avoided in the vast majority of cases. Although the ACE does not explicitly detail standards for patterns of practice, the ACE statistically implies deflections from quality care and thereby strongly encourages the development of such standards. The encouragement will be strongest for those medical interventions related to the avoidable ACE outcomes, but will also exist for injuries not included in the ACE listing. Moreover, related guidelines for quality will inevitably be broader than the

Sanazaro \& Don Harper Mills, A Critique of the L'se of Cenetic Screening in Quality Assessment, $265 \mathrm{~J}$ Am Med Ass'n 1977 (April 17, 1991).

89. See sources cited in note 25 . 
beginning listings of ACEs. For instance, whereas an ACE applies to instruments left within a patient's body, quality guidelines prompted by this category would begin to deal with such matters as problems resulting from an instrument falling into the body, even where it was subsequently discovered and removed. The resulting guidelines may be institution-specific or jurisdiction-wide, and their admissibility into courtrooms will vary. ${ }^{90}$ But the result, whether enforced through malpractice law, ACE process, or professional culture, should be improved care and lessened defensiveness.

The impact of ACEs would occur in several phases: first, the mere fact of ACEs would help focus attention on avoidable bad outcomes in covered areas of medical care. Second, a research-like phase would compile data and monitor performance. Third, feedback of data, through education, sanctions, or encouragement, would help to determine and alleviate underlying causes of ACE problems. Fourth, under payment reform, fiscal incentives would augment professional ones.

3. Keducing Defensive Medicine. ACE reforms should cut defensive medical practices. Defensive medicine is essentially a response to the ambiguity of current standards of care, as applied in a legal process that providers find unpleasant and unpredictable. Where ACEs supplant legal process to govern payment, doctors need not fear liability, and unproductive defensiveness has no reward, as already noted. ${ }^{91}$ ACEs have many of the virtues of guidelines in terms of reassuring practitioners that they will not be held liable arbitrarily for bad outcomes. Moreover, it is a criterion in the process of creating ACE listings that they have no undesirable incentive effects, which should preclude their creating new incentives for defensive medicine. ${ }^{92}$

Nonetheless ACEs should also have an impact even where a residual tort system survives after ACE reform or where ACE reform has not sought to replace the current tort system for medical injuries-because ACEs are focused on quality reform alone, for example. The reason is that improved quality signals will reduce the need for unproductive, legally oriented defensiveness even as they improve medical practice, and, eventually, outcomes of care. By highlighting appropriate procedures, such standards would isolate and discourage the use of unnecessary and unproductive interventions, which can lead not only to inconvenience and expense for the patient, but also even to injury from invasive procedures (using dyes,

90. ACEs themselves, especially where used for nontort payment purposes, might not be considered probative in a tort proceeding. See, for example, James A. Henderson, Jr., Uses Of DEC Lists, in Am Bar Ass'n, Feasibility Study at 49-51 (cited in note 10). However, broader quality guidelines, especially where adopted as the practice of an institution, seem quite likely to be admissible. Practice guidelines are often explicitly designed to have influence in tort cases. See sources cited in note 25 .

91. See text accompanying notes 33-35. Note that ending the purely legal incentive to be defensive may not end defensiveness, which continues to be rewarded by the earnings associated with defensive procedures. The same is true for all legal reforms.

92. We recognize that defensive medicine is a complex issue and there are many reasons for defensiveness. See Tancredi \& Barondess, 200 Science 879 (cited in note 4). Therefore, ACEs alone cannot eliminate defensiveness, but they can make a strong contribution. 
catheters, and the like). ACE-induced guidelines have the additional advantage of growing out of a specifically outcomes-oriented approach, which is generally conceded to be the appropriate orientation of quality incentives wherever practicable. ${ }^{93}$ In contrast, much of the conventional impetus for guidelines derives from utilization review, attempts to control medical spending by penalizing length-of-stay outliers and the like. ${ }^{94}$

Once set, these practice standards would help provide the quality backdrop in malpractice cases for determining when medical interventions have deflected from acceptable care, even if they were not formally admissible in evidence. ${ }^{95}$ As such, ACE-generated standards of practice may be nearly as influential in minimizing unnecessary procedures as would ACEs, were they accepted as a replacement for much of the tort system.

\section{V}

\section{Further Developments in Preparation for Testing}

ACEs are ready for actual demonstrations of their effects. As part of planning for implementation to proceed, some additional systems design is needed. Remaining details are not conceptually difficult, although they will take time and willing support from implementing states, hospitals, HMOs, or other entities. This section briefly considers these prerequisite steps; full implementation will call for more detailed elaboration. A payment reform that replaces much or most of the current tort system through mandatory legislation calls for the most additional preparation. Voluntary adoption of ACEs for other reforms requires less.

\section{A. Further Refinement and Expansions of ACE Listings}

The first step toward implementation of any ACE-based reform is to further improve the current ACE listings. As now constituted, they are sufficiently well specified for research applications by well-motivated and disinterested analysts. But they need some additional work before they will be comprehensive, specific, and reliable enough for uses that affect rights and responsibilities in the real world. This is true whether large sums of money are at stake, as in payment reform, or whether only hospital monitoring of its staff's own inpatient practice is involved.

Start with comprehensiveness. The three medical specialties for which ACEs have been created are the most important: general surgery, orthopedic surgery, and obstetrics and gynecology are the top three in frequency of

93. See generally, Office of Technology Assessment, The Quality of Medical Care: Information for Consumers (US Gov't Printing Office, June 1988).

94. See, for example, Kinney \& Wilder, 22 UC Davis L. Rev at 421 (cited in note 25); Troyen Brennan, Practice Guidelines and Malpractice Litigation: Collision or Cohesion?, $16 \mathrm{~J}$ Health Pol, Pol'y \& L 67 (1991).

95. Voluntary use of definitive standards can be expected to aid in reliable and less expensive settlement of cases short of trial. This is what underlies the value of ACEs for dispute resolution and for screening panels. 
current malpractice claims against physicians. According to the national GAO survey of 1984 closed claims, ${ }^{96}$ these three specialties account for 33 percent of all claims against doctors. However, no specialty treats patients completely in isolation. Although the generation of ACE lists must be specialty specific to be professionally credible, ACEs in practice need to apply to episodes of patient care that involve numerous specialties.

Hence, it is important to expand the listings to related specialties, starting with those that directly complement the three specialties already covered. These areas include anesthesia, which often accompanies childbirth or surgery, radiology, pathology, and possibly also emergency room care. Adding these four specialties, accounting for an additional 15 percent of current claims against physicians, would bring the total to nearly one half of all claims. ${ }^{97}$ It is also desirable to include areas of medicine that offer alternatives to ACE-covered specialties, so as not to skew clinical choices among them-including nurse midwives along with obstetricians, and nurse anesthetists along with anesthesiologists. Along these same lines, the ACE lists need to be recast in patient rather than physician terms, that is, written to be applicable to episodes of patient care regardless of the specialties involved in diagnosis and treatment.

In the future, other categories of surgery, such as plastic surgery, urology, ophthalmology, neurosurgery and otolaryngology should be added. Ultimately, it seems desirable to cover all of inpatient care as well as its outpatient care substitutes, such as surgicenter or urgicenter care. ACEs for care completely outside the hospital environment are a longer term goal. ${ }^{98}$

Next, it is important to improve the drafting of ACEs for practical implementation. This drafting will include both improvements of medical precision and sensitivity to the legal factors that must be considered for creating an implementable list. Areas of ambiguity need to be addressed, or they will foment disputes potentially requiring litigation or other expensive processes to resolve.

Action also needs to be taken to improve the professional/political credibility of ACE listings. This means using a more formal process to promulgate listings (and developing mechanisms for periodic updating) and otherwise convincing the professions and the public that the methodology is sound. There must be widespread confidence that the lists accurately comport with the stated criteria of avoidability and that they can be fairly implemented in practice. A particular concern is that different reviewers applying the same list should reach the same result in most cases (a standard, incidentally, by no means met by the current system of litigation). This calls

96. US Gen'l Acct'g Office, Claims Closed in 1984 at 54, Table 4.2 (cited in note 31).

97. Id.

98. Most malpractice is associated with hospital care. See, for example, id at 24-35, Table 2.8. 
for some further preliminary testing of ACEs on actual cases during planning for implementation. ${ }^{99}$

\section{B. Decisions on Administration and Financing}

Any ACE reform must also specify its administrative design. As for other injury-payment systems, a number of models are feasible. Administration, financing, and bearing of risk about uncertain future losses-all these can be either public, private, or a combination of the two. Today's liability system features public-private administration (trials and settlements of courtsupervised litigation), but private risk bearing (through insurers) and financing (through providers' premiums), although there have been public interventions in the insurance markets. No-fault auto insurance reform, on the other hand, sought to make liability determinations more private by minimizing litigation, continuing private financing and risk bearing as well. In the workers' compensation reform model, administration is public (by an agency), but risk bearing and financing are private. Premiums are paid to private insurers, which assume the risk of meeting future obligations determined by the public agency's process. As a final example, for Social Security disability coverage, administration, financing, and risk bearing are all public.

Choosing among such options is a matter for an implementing jurisdiction to decide. We expect that many or most will prefer public administration as under the workers' compensation model for reasons of political culture and constitutionality (the latter in the expectation that many courts would look askance on replacing litigation with private insurance). ${ }^{100}$ Private financing and risk bearing, also on the workers' compensation model, seem likely in many or most states because of the recent public distaste for "on-budget" financing ${ }^{101}$ and because private malpractice insurance is so well established. ${ }^{102}$

99. Applying the improved ACE listings to respected data bases will help establish their power through processes such as testing of "inter-rater variability," as social scientists term variation in judgments. This examination will be essential in determining the robustness of the ACE approach as a scientifically acceptable method for addressing compensation and accountability. Further research is underway to begin to address inter-rater variability. See note 63 .

100. A full discussion of the constitutionality of different specifications of ACE-based reform goes beyond the scope of this article. We note in passing that the judicial record of even conventional, "less of the same" tort reforms is better than their reputation would suggest. Bovbjerg, 22 UC Davis L Rev at 547-48 (cited in note 6). For good discussions of state court approaches, see David $R$. Smith, Battling a Receding Tort Frontier: Constitutional Attacks on Medical Malpractice Laws, 38 Okla L Rev 195 (1985) (judicial reactions to conventional tort reforms as of the mid-1980s); Bovbjerg, Sloan \& Blumstein, $83 \mathrm{Nw}$ U L Rev at 965-74 (cited in note 75) (more recent judicial trends and more thoroughgoing reform proposal).

101. Recent political history, especially at the federal level, is of course an object lesson of opposition to new tax-funded initiatives. See, for example, R. W. Apple, Jr., The Big Vote ls for "No," NY Times Al, col 4 (November 8, 1990); Andrea Stone, Voters Turn Tight-Fisted; Theme: "Hold Line on New Spending," USA Today A l, col 4 (November 8, 1990). There are indications that state voters can support new initiatives where they are clearly specified and receive limited funding.

102. The same private insurer could be responsible for both tort liability and ACE responsibility for the same type of claim. This would raise special problems of gaming, wherein obligations might be shifted whichever way was more fiscally advantageous. Of course, the ACE/tort boundaries would 
Another part of administration is the process by which the administering entity makes and applies decision rules. The ACE listings are the most central set of rules, but many others are needed, including a way to update the listings periodically. In a public model, most such choices are matters of administrative law that would be addressed only after enactment of enabling legislation. This article accordingly does not seek to specify anything like a full set of operating procedures. We do wish to re-emphasize, however, that the appropriate model to follow is generally that of first-party insurance or social insurance rather than a formal adversarial process like litigation. (In this regard, workers' compensation, with its adversarial case-by-case methods of determining injury and causation, seems a less useful precedent.)

Basically, ACE processes should be informal, although some formal investigatory powers are needed (whether created by law or by private contract), and there should be an internal dispute resolution and appeals mechanism of some sort. Judicial appeals should be strictly limited-to something like the abilities to sue for breach of contract (for private process), or to obtain judicial review of public administrative decisions for arbitrary and capricious behavior (for public process). There should not be routine access to courts for a new fact-finding procedure; the goal is an alternative system with different standards for decisions, not a pretrial screening process. ${ }^{103}$

With regard to financing, as a matter of principle, medical providers and other defendants in medical injury actions should pay for much if not most of the system, although there is also an argument for some subsidy, ${ }^{104}$ even for

be pushed from both directions by patients and providers, in any case, depending on which was more advantageous in a particular case. ACEs are meant to be robust and objective enough to resist such border maneuvers.

103. We note here that it is anticipated that the medical system would itself take notice of ACEs' occurrence and take appropriate actions. In this regard, there is a need to improve medical records' usefulness as documentation of injury. For our ACE research, we compared the medical records of a large medical center with subsequent risk management/legal defense records about the same hospital services. We found evidence of sorne medical problem in the majority of cases that later attracted legal attention, but not necessarily the same problem as was complained about. In every case, it was far easier to understand events and reach judgments about the likely avoidability of harm using the legal records. This is perhaps partly explained by providers' fears that too vigorous disclosure in discoverable records could hurt in court. Compare Stanley J. Reiser, The Influence of Malpractice Litigation on the Safety of Patients, in Robert E. Litan \& Peter W. Huber, eds, The Liability Maze: The Impact of Liability Law on Safety and Innovation 227 (Brookings Institution, 1991). It may also partly explain why the New York study did not find better accord between legal filings and hospital records. See note 54 . In any event, medical records need improvement to help serve an ACE-based payment system or ACE-based monitoring system.

104. Fiscal incentives linked to credible statistical patterns and guidelines for improvement definitely should motivate improved outcomes. However, fiscal responsibility could also promote a disinclination to cooperate with an ACE system or even outright evasion and refusal to enter key aspects of bad outcomes in medical records. Hence, there is justification for preventing the fiscal impact of any one case from being too large. One possible source of subsidy for physicians is the hospital. Keeping the fiscal responsibility at the hospital level would also maintain deterrence within the medical system. Compare Myron F. Steves, A Proposal to Improve the Cost to Benefit Relationships in the Medical Professional Liability Insurance System, 1975 Duke L J 1305, 1327-28 (quality incentive of institutional liability). Also, it may well be harder for an institution to be uncooperative than for an individual. 
public contribution. ${ }^{105}$ One goal of ACE-based reform is to improve fiscal signals for deterrence, as well as to clarify professional responsibility through the lists. How much providers pay should depend on their risk classification, as under today's liability insurance. Moreover, rates should partly reflect insureds' personal or institutional experience under the system. Again, such merit rating is a goal of ACE-based reform. A particular issue for implementing entities to address is how multiple practitioners involved in a single event should split their responsibility, eventually to be reflected in premiums. Self-insured hospitals that cover their medical staffs face this issue today. Where possible, we would prefer to leave this matter to private decision. ${ }^{106}$

\section{Rules on Damages}

To implement an ACE payment system, new rules of damages will be needed also. Conceptually, ACEs lie between a fault-based deterrent system and a full no-fault compensation system like the New Zealand system or workers' compensation. Damage amounts therefore should logically be less than under the fault-based system, but higher than those under full no fault. ${ }^{107}$ Politically, it may also be important to raise payment levels above workers' compensation amounts, which can seem very low relative to tort norms. ${ }^{108}$ Procedurally, the process of settling ACE claims should strive to achieve similar results in similar cases. The key to this is developing objective rules and applying them even-handedly.

Current judicial practice makes juries (and private negotiators) treat each case's losses as wholly idiosyncratic and gives virtually no guidance based on previous results. ${ }^{109}$ Not only are resulting damage awards frequently unfair as between similar cases, but the system also makes outcomes extremely hard to predict for litigants and insurers alike. In contrast, an insurance system based on ACEs should be able to achieve far more even-handed and predictable results.

Consider, first, injured parties' pecuniary losses. The goal here should be to compensate them reasonably without having to engage in lengthy and expensive arguments about imponderables. Past expenses can be reimbursed at documented levels. Many losses, however, even pecuniary ones, are not

105. Public contribution can be justified by the public interest in curtailing medical defensiveness and in promoting improved quality signals, both in connection with public health and in administration of the largest medical payers, Medicare and Medicaid. The justification is stronger if particular new procedures are adapted along with ACEs to address defensive medicine. However, physicians have no general claim on public revenues to pay insurance bills.

106. Prior writing has also addressed these issues. See Havighurst \& Tancredi, 51 Milbank Mem Fund $Q$ at 129-30 (cited in note 15); James A. Henderson, Putting the DCE Lists to Work: Alternative Approaches to Establishing a Compensation System for Victims of Medical Accidents, in Am Bar Ass'n, A Feasibility Study at 53 (cited in note 10).

107. Bovbjerg, Sloan \& Blumstein, $83 \mathrm{Nw} \mathrm{U} \mathrm{L} \mathrm{Rev} \mathrm{at} 917$ (cited in note 75).

108. Adopting workers' compensation approaches to damages, however, does have the virtue of being judicially familiar and having passed constitutional challenge. Personal communication with Professor Jeffrey O'Connell.

109. See generally id. 
precisely ascertainable, even with individualized courtroom trials. These include imputed values (like lost housekeeping services of a family's caregiver) and future losses (such as disability and medical care). Future wage loss should be standardized insofar as possible, to avoid guesswork and disputation. Future services should to the extent possible be paid as incurred, preferably with incentives for cost containment. It should be possible to assure continuing payment of the needs of the severely injured, while letting market forces determine appropriate discount rates and other elements of valuing future losses. ${ }^{110}$

It should also not be difficult to standardize the approach to frequently occurring ACEs. In particular, for "bad baby" cases, the valuation of wage loss anticipated should be scheduled so as to treat unfortunate children alike, and medical need determinations could begin from standardization of expectations developed by experts within an implementing agency or insurer. ${ }^{111}$

A major open issue is what rules should apply to losses met by collateral sources. Many states have begun to require offsetting recoveries from private insurance from liability claims. In no case should there be recovery by injured people, which can reward malingering. ${ }^{112}$ Offset reduces malpractice premiums, but does not make medical providers fully responsible for their failure to prevent avoidable problems in the ACE context. A different approach would be to pay such losses, but to pay them back to whatever other third party had already incurred them, or to pay them on a periodic basis for losses to be incurred.

Second come nonpecuniary losses, including pain and suffering, loss of enjoyment of life, and inconvenience. Such losses are very real despite their intangible nature; people are willing to make financial and other sacrifices to avoid them, so they should be recognized in some fashion. ${ }^{113}$ But by their nature they are not amenable to conventional methods of valuation, nor should full tort valuation be adopted. Hence, the scheduling approach seems especially promising. Systematizing such valuation will make payments evenhanded and help minimize disputes. One approach is to use a matrix of relative values derived from severity of injury and likely duration, perhaps

110. James F. Blumstein, Randall R. Bovbjerg \& Frank A. Sloan, Developing Better Tools for Assessing Damages for Personal Injuries: A Common Law of Damages and Insurance Contracts for Future Services, 8 Yale J Reg 171 (Winter 1991).

111. For a research-oriented approach to standardizing expectations of future costs in two highcost types of cases, see Frank A. Sloan \& Stephen S. van Wert, Cost and Compensation of Injuries in Medical Malpractice, 54 L \& Contemp Probs 131 (Winter 1991).

112. On the extent of offset provisions, see Bovbjerg, 22 UC Davis L Rev at 526 (cited in note 6); on their effect on premiums for liability coverage, see Stephen Zuckerman, Randall R. Bovbjerg \& Frank A. Sloan, Effects of Tort Reforms and Other Factors on Medical Malpractice Insurance Premiums, 27 Inquiry $167(1990)$. For a debate on collateral source offset versus subrogation by the collateral sources, see Am Bar Ass'n, Feasibility Study at 8, 66-67 (cited in note 10) (Commission for offset; Professor Anderson for subrogation).

113. Ted R. Miller, Willingness to Pay Comes of Age: Will the System Survive?, 83 Nw U L. Rev 876, 87889 (1989). 
measured by age. ${ }^{114}$ The amount of compensation is a matter of social choice for each jurisdiction or entity adopting an ACE-based payment reform. Considerably lower limits for the upper end of injuries seem appropriate, while some organized allowance for lesser injuries also seems proper.

In all, a successful approach to damages will require a marriage between a good set of general rules and a reasonable practice for implementing them. Any process will have to make judgments about borderline cases, to address new problems unforeseen in the drafting of the rules, and provide periodic updates of damage allowances.

\section{Estimating the Incidence of ACEs}

The most troublesome outstanding issue about an ACE-based payment reform is the extent of the inducement effect. ${ }^{115}$ To address this question better, we need to know the incidence of ACEs, as now defined and after refinements in the listings. Incidence plus extent of injury as measured under a set of damage rules will determine system cost. Questions about cost are apt to make it necessary to investigate further as states and other implementing entities consider assuming or imposing new fiscal ACE-related obligations. Good prediction will be of the essence if there is to be private risk-bearing, as insurers simply will not underwrite a novel form of coverage without credible expectations, public reinsurance, or both. ${ }^{16}$ Public funding, on a pay-as-you-go basis, could begin operations without the same degree of actuarial confidence, as Indiana's Patient Compensation Fund did in 1975.117 Yet, today's politicians and taxpayers want not dissimilar reassurances about cost as well.

Hence, a major implementation-planning task is to assess ACE incidence in one or more areas. Applying the improved ACE listings to respected data bases will provide us with additional information on the incidence of these events in various contexts and under different definitions of ACEs. Plans are under way to do so. ${ }^{118}$

\section{E. Moving to Implementation Through Demonstrations}

ACEs' potential value has been well documented. However, some practical uncertainties and doubts remain, and different social value judgments are possible about implementation. Hence, the logical strategy is to approach a full payment reform only incrementally. Payment reform might best begin with a single area of medical service, such as childbirth, a particular problem under current liability practice.119 Moreover, if ACEs show their

114. Bovbjerg, Sloan \& Blumstein, $83 \mathrm{Nw} \mathrm{U} \mathrm{L} \mathrm{Rev} \mathrm{at} 938$ (cited in note 75).

115. See Part IVB2.

116. Clarity of payment rules, as well as a body of data on which to base actuarial projections, will be very important for a scheme to be implementable.

117. Kinney \& Gronfein, 54 L \& Contemp Probs at 186 (cited in note 82).

118. See note 50 .

119. See generally Rostow' \& Bulger, eds, Liability and Obstetrical Care (cited in note 29); Bovbjerg, Tancredi \& Gaylin, $265 \mathrm{~J} \mathrm{Am} \mathrm{Med} \mathrm{Ass'n} 2835$ (cited in note 17). Virginia and Florida have indeed 
practicability through the "lesser" reforms-for quality monitoring, as well as voluntary reform of insurance and dispute resolution-the way will be paved for subsequent adoption of payment reforms based on ACEs. We expect payment reform to be approached through step-by-step demonstrations rather than through immediate, global reform.

Thus, ACE lists can be refined and tested before large sums of money depend on the resolution of boundary disputes. The likely incidence of ACEs in particular hospitals or states can be ascertained before new financial responsibility for them is established. And damage rules could be modeled before being actually enforced in practice. Still, to make these kinds of further progress, the ACE concept needs to move from research and law reviews into reality, in the form of practical demonstrations. This strategy calls for one or more states or large private entities to adopt an ACE-based strategy for one or more of the uses described here.

\section{VI \\ Conclusion}

The ACE approach to malpractice reform has evolved during three generations of development. First came early conceptualization. Next, ACEs and implementing systems were more fully specified and applied in preliminary fashion. The most recent research has seen expanded listings, more structured professional development, and the first empirical testing on detailed sources of information about medical care and liability insurance. ACEs now exist for obstetrics/gynecology, general surgery, and orthopedic surgery.

ACEs' use as a payment reform has been more discussed than its uses for improving dispute resolution, insurance practice, or quality assurance. Research to date, most notably for obstetrics/gynecology, has confirmed that ACEs:

- are definitely feasible to develop and apply in research;

- will almost certainly cover more injuries on a more regular basis than the liability system;

- can clearly remove most serious injuries and most dollars from litigation, at least in obstetrics, which is a major problem area;

- can almost certainly achieve administrative savings on handling each claim;

- are rather unlikely to promote large numbers of expensive new cases; and

— will almost surely mean less aggravation for all concerned.

reformed tort law for childbirth, listing one very narrowly defined category of adverse outcome for no-fault payment. 
ACE-based payment reform to replace much or most of the tort system would combine improved compensation with improved deterrence. A reformed insurance system would improve payment for today's avoidable injuries; and its more credible, outcomes-based incentives for practitioners would help avoid tomorrow's. All this seems possible without the major drawbacks of a fault-based system of litigation.

Payment reform thus holds both near-term and long-term benefits, for both patients and practitioners-quite unlike conventional tort reform, which simply curtails tort remedies in the short run. Yet ACEs can do more than provide a viable basis for an insurance alternative to the (appropriately) beleaguered tort system with respect to most serious injuries. ACEs can also help improve existing insurance practice and legal processes as well as promote better quality monitoring and feedback-even short of replacing most of the tort system.

Most of the arguments against ACE payment reform have been effectively addressed. At this point, the probable merits and possible shortcomings of ACEs are well documented, at least in research terms. What remains to establish is the robustness of any ACE system in practice and the expense of medical injuries it could cover as an alternative to the existing tort system. (ACEs would also supplement or supplant the non-tort funds that provide most help to victims of medical injury.) ACEs exist and are now ready for their final "fine tuning" prior to actual implementation. ACE reforms merit demonstrations that their virtues will survive the move from theory to practice and that any problems are manageable. Further ACE development will proceed best under the spur of real-world exigencies.

The next generation of ACE work needs to convince practical peoplestate legislators as well as health care providers-that versions of ACEs deserve the chance to demonstrate their practicality on their own. As a way of protecting against the down-side risk of potentially high-budget (but low net cost) payment reform, we expect reforms to start with less thoroughgoing uses and to work up to full applications as a payment reform. Only practical experience can make definitive assessments. It is time for field tests. 
